\title{
A Conceptual Framework of Applying Information Technology Innovation for Solving Societal Issues/Challenges: A Case of Obesity versus Diabetes
}

\author{
Yekini, Nureni Asafe \\ Olukumoro Olugbenga \\ Aigbokhan Edwin \\ Department of Computer Technology \\ Yaba College of Technology, Lagos, Nigeria
}

\section{Doi:10.5901/jesr.2013.v3n9p155}

\begin{abstract}
A social issue, challenges, ill is an issue that relates to society's perception of people's personal lives. Different societies have different perceptions and what may be "normal" behavior in one society may be a significant social issue in another society. Obesity is a prevalent social problem in today's society, with rates steadily increasing. Obesity is a medical condition in which excess body fat has accumulated to the extent that it may have an adverse effect on health, leading to reduced life expectancy and/or increased health problems. Obesity increases the likelihood of other diseases especially type 2 diabetes. An individual with Obesity challenge is likely to have diabetes. Diabetes is a chronic disease that needs to be regularly monitored to keep the blood sugar level within normal ranges. The frequent visit to the main hospital seems to be tiring and time consuming for diabetes and obesity patient. Consequents to this, the author of this paper proposed the design of web-based electronic monitoring system for monitor and management of Diabetes in obesity patients. The system will provides a daily monitoring and monthly services. The daily monitoring will includes recording the result of daily analysis and activates to be transmitted from a patient's mobile device to a central database. The monthly services require the patient to visit a nearby care center for medical examination. The result of this visit entered into the system and then synchronized with the central database. Finally, the endocrinologist can remotely monitor the patient record and adjust the treatment plan and the insulin doses if need.
\end{abstract}

Keywords: Endocrinologist, Diabetes, Obesity, Social issues, electronic monitoring system, webbased, Information Technology

\section{Introduction}

Information technology is a contemporary term that describes the combination of computer technology (hardware and software) with telecommunications technology (data, image, and voice networks). Information Technology is at the root of information systems Yekini and Oyeyinka (2013).

This information technology has become a household term and tool in every human endeavors to extend that people are learning and discovery new ways of applying it in solving problems. There is no area of human endeavors where use of information technology is not applicable. Consequent to this I say:

If there is anybody that is not IT literate either partly or fully as at year 2010 up to date, such individual is living but not existing. Because he or she is static (not moving) with the dynamic 


\section{world we find ourselves.}

To be IT literate, an individual must be aware of the term IT and it tools, learning and obtains knowledge about IT and interact with IT tools regularly. Yekini and Lawal (2011).

Information Technology is one of the major tools available in the area of application of scientific and technological innovations in solving societal issues, i.e. an issue that relates to society's perception of people's personal lives. it is important to improve the methodologies, procedure and techniques of managing as it consequents may be disastrous to the nation at large. Some social issues can result to war. Some social issues/challenges are: unemployment, as of October 2012, unemployment is social issue in United States of America as their unemployment rate becomes 7.8 percent. Dewan, Shaila. (2012). Obesity versus diabetes mellitus, a medical condition in which excess body fat has accumulated to the extent that it may have an adverse effect on health, leading to reduced life expectancy and/or increased health problems. Haslam and James (2005). The term diabetes mellitus includes several different metabolic disorders that all, if left untreated, result in abnormally high concentrations of a sugar called glucose in the blood.

The main focus of this research work is on propose of conceptual framework for use of information technology innovation in monitoring and management of Obesity versus diabetes in patients so that an individual suffering such social issue don't needs to be going to hospital regularly for medical check-up as that may be time tiring, time consuming and aggravate other issues related to their current problem e.g heart disorder.

The documentation of this research write-up is organized as follows; in section II, literature survey which include the collection and summary of discussion of various social issues and some area of applying computer in medicine. In Section III, we presents the system architecture and describe it modes of operations which include how it various components will work together to archive the set objective. Section IV, presents the design and implementation of the system. And finally in section V, we present the recommendation, conclusion and highlight some future works required in application of Information Technology managing some other medical societal challenges like abortions, HIV/AIDs etc.

\subsection{Objective of the Study}

The objectives of the study are

- To design and implement the Web-Based electronic monitoring system for management of obesity versus diabetics.

- to add a general physician role to the system in order to balance the load with the endocrinologist; the general physician will have a preview privilege with an authority to insert new test examination. Each test examination result is associated with the doctor id for the doctor who did it. So, the endocrinologist will know who did this examination for the patient.

\subsection{Purpose of the study}

The purpose of this study is to analyze the past and current position of social challenges and to highlights how the information technology innovation can play role in management of social challenges especially the challenges associated with medical world.

\subsection{Research Questions}

Based on the overall objective stated i.e. design and implement of the Web-Based electronic monitoring system for management of obesity versus diabetics.

The major research questions is to what extent will proposed system assist in managing and 
monitoring of the said medical social challenges.

\subsection{Scope and Limitation of the Project}

The scope of this project is within medical social challenge's and it is application is currently obesity versus diabetes as social challenges.

\subsection{Problem Statement}

The burden of obesity versus diabetes is growing with 347 million people currently affected worldwide (Danaei et al 2011) and numbers projected to increase to 552 million by 2030. In the UK, the cost to the National health Service (NHS) related to diabetes in 2002 was estimated to be around " $€ 1.3$ billion a year, with most of this cost arising from the long-term complications resulting from diabetes not being managed properly", the International Diabetes Federation (IDF) suggests that in the developed world the cost of caring for patients with diabetes is double that of the background population (International Diabetes Federation 2011).

Consequents to this it is important to improve the methodologies, procedure and techniques of managing this social issue. Improving blood sugar control in patients with obesity versus diabetes can reduce the risk of death and microvascular complications which this paper is focused on.

\section{Literature Survey}

\subsection{Social/ssues}

This is an issue that relates to society's perception of people's personal lives. Different societies have different perceptions and what may be "normal" behaviour in one society may be a significant social issue in another society. Social issues are distinguished from economic issues. Some issues have both social and economic aspects, such as immigration. There are also issues that don't fall into either category, such as wars. Some perceives social issues are discussed below:

Agism: Throughout the life course there are social problems associated with different ages. One such social problem is age discrimination. An example of age discrimination is when a particular person is not allowed to do something or is treated differently based on age. Inequality Inequality is "the state or quality of being unequal". Inequality is the root of a number of social problems where things such as gender, race and age may affect the way a person is treated. A past example of inequality as a social problem is slavery in America. Africans brought to America were often enslaved and mistreated, and did not share the same rights as the white population of America (ex. voting). Dictionary.com (2013)

\subsection{Abortion}

Abortion is split between pro choice and pro-life. Pro choice people believe abortion is a right that women have that shouldn't be limited by government. Pro life people believe personhood begins at conception so abortion is the wrongful killing of an innocent person.

\subsection{Valence /ssues}

A valence issue is typically a social problem that is uniformly agreed upon. These types of issues generally generate a widespread consensus and provoke little resistance from the public. An example of a valence issue would be incest or child abuse. Unlike a valence issue, a position issue typically outlines a social problem in which the popular opinion among society is divided. An 
example of a position issue is vegetarianism or veganism, due to the lack of widespread consensus from the public. Nelson, Barbara J (1986).

\subsection{Obesity versus Diabetes}

Obesity is a prevalent social problem in today's society, with rates steadily increasing. Obesity is a medical condition in which excess body fat has accumulated to the extent that it may have an adverse effect on health, leading to reduced life expectancy and/or increased health problems. People are considered obese when their body mass index (BMI), a measurement obtained by dividing a person's weight in kilograms by the square of the person's height in metres, exceeds 30 $\mathrm{kg} / \mathrm{m} 2$. Haslam DW, James WP (2005).

Obesity increases the likelihood of various diseases, particularly heart disease, type 2 diabetes, obstructive sleep apnea, certain types of cancer, and osteoarthritis and obesity has been found to reduce life expectancy. Haslam DW, James WP (2005). Obesity is most commonly caused by a combination of excessive food energy intake, lack of physical activity, and genetic susceptibility, although a few cases are caused primarily by genes, endocrine disorders, medications or psychiatric illness. Evidence to support the view that some obese people eat little yet gain weight due to a slow metabolism is limited; on average obese people have a greater energy expenditure than their thin counterparts due to the energy required to maintain an increased body mass. Kushner, Robert (2007), Adams J P, Murphy PG (2000).

Dieting and physical exercise are the mainstays of treatment for obesity. Diet quality can be improved by reducing the consumption of energy-dense foods such as those high in fat and sugars, and by increasing the intake of dietary fiber. Anti-obesity drugs may be taken to reduce appetite or inhibit fat absorption together with a suitable diet. If diet, exercise and medication are not effective, a gastric balloon may assist with weight loss, or surgery may be performed to reduce stomach volume and/or bowel length, leading to earlier satiation and reduced ability to absorb nutrients from food.Imaz I, et al, (2008).

Obesity is a leading preventable cause of death worldwide, with increasing prevalence in adults and children, and authorities view it as one of the most serious public health problems of the 21st century. Barness LA, Opitz JM, Gilbert-Barness E (2007). Obesity is stigmatized in much of the modern world (particularly in the Western world), though it was widely perceived as a symbol of wealth and fertility at other times in history, and still is in some parts of the world. Haslam DW, J ames WP (2005), Woodhouse R (2008).

Excessive body weight is associated with various diseases, particularly cardiovascular diseases, diabetes mellitus type 2, obstructive sleep apnea, certain types of cancer, osteoarthritis and asthma. Haslam DW, James WP (2005), Poulain M, Doucet M, Major GC et al. (2006).

\subsection{Hate crime}

In both crime and law, hate crimes (also known as bias-motivated crimes, or race hate) occur when a perpetrator targets a victim because of his or her perceived membership in a certain social group. Examples of such groups include but are not limited to: racial group, religion, sexual orientation, ethnicity or gender identity. Stotzer, R (2006). Hate crime is a category used to describe bias-motivated violence: "assault, injury, and murder on the basis of certain personal characteristics: different appearance, different color, different nationality, different language, different religion. Streissguth, Tom (2003). "Hate crime" generally refers to criminal acts that are seen to have been motivated by bias against one or more of the types above, or of their derivatives. Incidents may involve physical assault, damage to property, bullying, harassment, verbal abuse or insults, or offensive graffiti or letters (hate mail). The issue is a social problem because it is widespread and affects much of our communities and the individuals who do not fit the norm. 


\subsection{Religious, Ethnics and Political Intolerance (Intergroup Relation)}

Many societies all over the world have had to grapple with the problem of inter-group relations. Such concepts as 'apartheid', 'discrimination', 'prejudice', 'pogrom', 'ethnicity,' 'hatred', 'fanaticism', 'intolerance,' 'war,' and 'terrorism', etc are terms in common use. The Jews, the "chosen people of God" divided mankind into themselves and the Gentiles. The Arabs on the other hand, regarded themselves as the noblest nation in comparison with all other nations. This egoistic feeling of the nations of the Middle East resulting in intolerance and discrimination has given rise to the many years of intractable Middle East question. Ojie, A.E (2002).

In relation to Nigeria, one of the greatest and most inhuman problems of inter-group relations witnessed in the country's political history is the civil war (1967-70). The Eastern region, under the leadership of Col. Odumegwu Ojukwu, seceded, declaring itself the Republic of Biafra. Thirty months of civil war began in July, claiming more than a million lives and devastating the Eastern region. Diamond, L (1995) Nigeria is composed of peoples with different religious, ethnic and cultural diverse backgrounds. Home to some 250 distinct linguistic groups, Nigeria has been proned to the intense politicization of ethnic and religious differences. Regional location and religion have served to reinforce the tripartite cleavage of the three dominant ethnic groups (Yoruba, Igbo and Hausa). The transfer of power from the military to civilian in 1999 witnessed a rising spate of ethnic, religious and communal conflicts with devastating consequences on lives and property. "It seems as if decades of bottled up anger under military rule have suddenly exploded and found expression in violent ethnic, religious and communal conflicts... no fewer than 40 violent ethnoreligious and communal conflicts were reported within the first three years of the return to civil rule in 1999.

\subsection{Other Social Issues}

Some other social issues include education, lack of literacy and numeracy, school truancy, violence and bullying in schools, immigration, and discrimination of all sorts, the role of women, gender issues, unplanned parenthood, and teenage pregnancy. Wikipedia (2013)

\subsection{Computer in Medicine}

\subsubsection{Mycin}

Mycin is an early expert system, or artificial intelligence (Al) program, for treating blood infections. In 1972 work began on MYCIN at Stanford University in California. MYCIN would attempt to diagnose patients based on reported symptoms and medical test results. The program could request further information concerning the patient, as well as suggest additional laboratory tests, to arrive at a probable diagnosis, after which it would recommend a course of treatment. If requested, $\mathrm{MYCIN}$ would explain the reasoning that led to its diagnosis and recommendation. Using about 500 production rules, MYCIN operated at roughly the same level of competence as human specialists in blood infections and rather better than general practitioners B.J. Copeland (2002).

Despite MYCIN's success, it sparked debate about the use of its ad hoc, but principled, uncertainty framework known as "certainty factors". The developers performed studies showing that MYCIN's performance was minimally affected by perturbations in the uncertainty metrics associated with individual rules, suggesting that the power in the system was related more to its knowledge representation and reasoning scheme than to the details of its numerical uncertainty model. Some observers felt that it should have been possible to use classical Bayesian statistics. MYCIN's developers argued that this would require either unrealistic assumptions of probabilistic independence, or require the experts to provide estimates for an unfeasibly large number of conditional probabilities. Buchanan, B.G., Shortliffe, E.H. (1984). Research conducted at the 
Stanford Medical School found MYCIN to propose an acceptable therapy in about $69 \%$ of cases, which was better than the performance of infectious disease experts who were judged using the same criteria. This study is often cited as showing the potential for disagreement about thereapeutic decisions, even among experts, when there is no "gold standard" for correct treatment. Heckerman, D. Shortliffe, E. (1992).

\subsection{Virtual Doctors}

The Virtual Doctor is either online or offline medical doctors that see his patients non-physically via HealthSpot. The virtual doctor uses computer-based system and some ICT tools to discharge it duties. In this case doctor doesn't see his patients physically. Some of the advantages of virtual doctor are; Doctor can pay better attention to other activities since patients can consult doctor offline, patients feel like doctors pay better attention to them during virtual visits, more convenient, automatic record-keeping, increased patient engagement thanks to screen sharing, a virtual waiting room is better than the physical one, and convenient for both patient and doctor. Jonah Comstock (2012).

\subsection{Telemedicine}

Telemedicine involves the use of ICT to deliver health care (information and services) to patients separated (from medical providers) by geographic boundaries [Bashshur, 1995]. Telemedicine is the use of telecommunication and information technologies in order to provide clinical health care at a distance. It helps eliminate distance barriers and can improve access to medical services that would often not be consistently available in distant rural communities. It is also used to save lives in critical care and emergency situations. Early forms of telemedicine achieved with telephone and radio have been supplemented with videotelephony, advanced diagnostic methods supported by distributed client/server applications, and additionally with telemedical devices to support in-home care Sachpazidis, Ilias (2008). telemedicine often refers only to the provision of clinical services while the term telehealth can refer to clinical and non-clinical services involving medical education, administration, and research Coach Newsham (2013).

\section{The System Architecture}

In this section III, we presents the system architecture and describe it modes of operations which include how it various components will work together to archive the set objective. The diagram below, figure 1 is the proposed system architecture. The proposed architecture will make up of the following sections that will be integrated together to form a whole System.

\subsection{Users Section}

There are three categories of user the user can access the system interface by logging to the system and assigned an access rights; the obesity versus diabetes patients, the Endocrinologist and general physician. This section will serve as the point of interaction between the users and proposed system. It contains the patient, the glucose meter, and the internet service that will enable the users to make connection with the system globally. The patient can manually enter daily food intake, physical activities and information about some medications and injection. The system will be design to; first alert the patient about injection time, special medicine reminder, date for medical examination and tests. And secondly also to enable patient to chat via exchanging messages with a general physician in case of emergency or inquiries. The general physician in the medical center is allowed to enter results of the HAlc (Hemoglobin Alc test is used as a standard tool to determine blood sugar control for patients with diabetes). The endocrinologist can remotely 
monitor the patients' status, send advises, and take an action in urgent cases. The endocrinologist is the only actor who allowed modifying the insulin doses regarding to the daily glucose reading and the result of the HAlc test. The endocrinologist can have the following functions by using the system:

- Preview patient record: shows record number, patient name, patient ID, Date of birth, and phone number.

- Glucose Injection: present the injection dose and whether the patient took it or not. The Endocrinologist has an ability to edit the glucose injection dose.

- Physical Examination: shows the last examination date, the HAlc result and physical examination result. The Endocrinologist has an ability to enter new test result for a specific patient.

- Appointments: shows the last visit, and the next visit.

Sometimes the endocrinologist needs to make an urgent appointment according to some results, HAlc result for example, so the endocrinologist will have authority to make an urgent appointment by specifying the date and the priority for this appointment.

- Insulin Doses: presents the doses for the insulin injection, the start date for these doses and for how many months. The endocrinologist has the ability to edit these doses and accept the changes.

\subsection{Service Section}

This will make up of Internet tools and some other information technology devices/tools such report extractor, web application servers, and smart analyzer for rendering services to the users section from database section. The service section is the core of the proposed system. It performs the services to the system units.

\subsection{Database Section}

This section will make up the databases for the system. The systems will depends on many data that make-up of databases such as: medical information's, patients' information, and users' information.

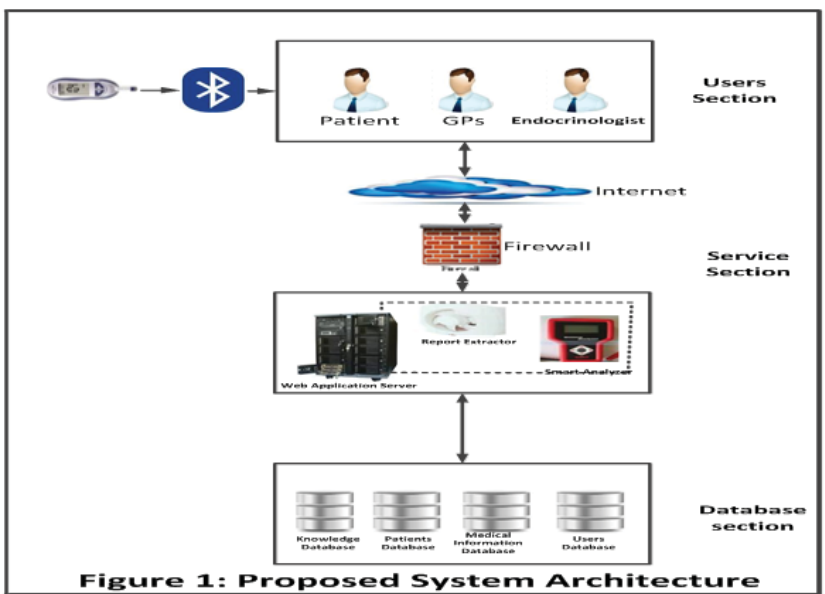

\section{Design And Implementation}

Section IV, presents the design and implementation of the proposed system. The design and 
implementation here is tentatively approved. It could be modified and change totally the period of the real implementation and design.

The system environment will be designed and implemented using java programming language. And we proposed multilingual (two or more language) support with reference English language having priority over other languages. Users can set their preferred language. This preferred selection is saved in the database. Once the user logged in to the system he/she preferred language will be retrieved, and according to the preferred language the application will launched with that language. The design will be flexible to support system more languages in future. Bluetooth Connectivity technology will been used in the proposed system. The Android platform support exchanging data over a Bluetooth network stack. The proposed system will use remote communication with central database to authenticate users log in information and also to retrieve/update patient medical information in the database. The communication process with MySQL database will be by posting data using HttpRequest. First, the application has to make a connection with a PHP script which locates in the server. This is done by use HTTP protocol. The system will provide send SMS. The patient can send SMS message to the endocrinologist throw the system.

The database section will be design with PHP MySQL database, and the doctor's information will contain privilege field that will contain one of the two values: 'ENDO' for the endocrinologist and 'GP' for the general physician. If the doctor has 'ENDO' privilege, this means that he/she have higher scope of functionality. These central databases will be installed using WampServer to synchronies the information between the clients. There will be two databases: 'accounts' database and 'dms' database. 'Accounts' database contains the users log in information. The data in account database will be used to authenticate users log in information. Once the application is authenticate the user, it will connect with the 'dms' database. 'Dms' database contains all the system relational tables such as: patient, doctor, appointment etc.

\section{Recommendation, Conclusion and Future Research Direction}

In this section $\mathrm{V}$, we present the recommendation, conclusion and highlight some future works required in application of Information Technology managing some other societal challenges like abortions, HIV/AIDs etc.

\section{Conclusion}

In this paper, we discuss A Conceptual Framework of Applying Information Technology Innovation for Solving Societal Issues/Challenges: A Case of Obesity versus Diabetes. We considered general physicians and endocrinologists as two major stakeholders in managing obesity versus diabetes. The general physician can do the medical checkups and examinations and feed the system with the results. The endocrinologist can access the system and request a report for a certain patient. $\mathrm{He} /$ she can modify the insulin doses and the treatment plan if needed. The architecture of the system is depends on three sections: Users Section, Service Section and Database Section. This system if designed and implemented it will reduce the amount of regular medical checkups and examinations a patient with obesity do. Hence reduce stress on general physicians and endocrinologists. It is highly recommended that scientist and IT professional to partner with other professional in other to studying the area application of scientific and technological application in solving various societal problems. This work involves the IT professional research alone, for widely acceptability, and usability of the proposed system. It is also recommended that professional general physician and endocrinologist been carried along towards the design and implementation of the proposed system. 


\section{References}

Adams JP, Murphy PG (July 2000). "Obesity in anaesthesia and intensive care". Br J Anaesth 85 (1): 91108. doi:10.1093/bja/85.1.91. PMID 10927998.

B.J. Copeland (2002). Description of Mycin, www.britannica.com/EBchecked/MYCIN ,22retrieved May .2013

Barness LA, Opitz JM, Gilbert-Barness E (December 2007). "Obesity: genetic, molecular, and environmental aspects". Am. J. Med. Genet. A 143A (24): 3016-34. doi:10.1002/ajmg.a.32035. PMID 18000969.

Bashshur, L (1995) On the definition and evaluation of telemedicine. Telemed J 1995

Buchanan, B.G., Shortliffe, E.H. (1984). Rule Based Expert Systems: The MYCIN Experiments of the Stanford Heuristic Programming Project. Reading, MA: Addison-Wesley. ISBN 978-0-201-10172-0.

Coach Ceo Don Newsham., About Telehealth: Telehealth Definition, Canadian Telehealth Forum. Retrieved from Coach:Canada's Health Teleinformatics Association website on August 25, 2012.

Danaei G, Finucane MM, Lu Y, Singh GM, Cowan MJ, Paciorek CJ, et al. National, regional, and global trends in fasting plasma glucose and diabetes prevalence since 1980: systematic analysis of health examination surveys and epidemiological studies with 370 country-years and $2 \cdot 7$ million participants. Lancet 2011; Vol. 378, issue 9785:31-40.

Dewan, Shaila. 2012. NY Times

Diamond, L "Nigeria" In Lepset, S.M. (ed.) The Encyclopedia of Democracy. Vol III (London: Routledge, 1995).

Wikipedia, Social issues available at: http:// www. wikipedia.org/wiki/Social issue Accesed may 2013.

Haslam DW, James WP (2005). "Obesity". Lancet 366 (9492): 1197-209. doi:10.1016/S01406736(05)67483-1. PMID 16198769.

Haslam DW, James WP (2005). "Obesity". Lancet 366 (9492): 1197-209. doi:10.1016/S01406736(05)67483-1. PMID 16198769.

Haslam DW, James WP (2005). "Obesity". Lancet 366 (9492): 1197-209. doi:10.1016/S01406736(05)67483-1. PMID 16198769

Heckerman, D. Shortliffe, E. (1992). "From certainty factors to belief networks". Artificial Intelligence in Medicine 4 (1): 35-52.

Imaz I, Martínez-Cervell C, García-Alvarez EE, Sendra-Gutiérrez J M, González-Enríquez J (July 2008). "Safety and effectiveness of the intragastric balloon for obesity. A meta-analysis". Obes Surg 18 (7): 841-6. doi:10.1007/s11695-007-9331-8. PMID 18459025.

International Diabetes Federation (2011), International Diabetes Federation. IDF 2011. http://www.idf.org/diabetesatlas/5e/the-global-burden 2011.

Jonah Comstock (2012)., Advantages of Virtual Doctor., www.mobihealthnews.com/22215/five-reasonsvirtual-doctor-visits-might-be May 8, 2013

Kushner, Robert (2007). Treatment of the Obese Patient (Contemporary Endocrinology). Totowa, NJ: Humana Press. p. 158. ISBN 1-59745-400-1. Retrieved April 5, 2009.

Nelson, Barbara J (1986). Making an Issue of Child Abuse: Political Agenda Setting for Social Problems. ISBN 9780226572017.

Ojie, A.E "Prejudice and Discrimination: A Sociological Overview of Inter-Group Relations in Nigeria." In Igun, U.A and Mordi, A.A (eds) Contemporary Social Problems in Nigeria. (Ijebu Ode: Shebiotimo Publications, 2002).

Poulain M, Doucet M, Major GC et al. (April 2006). "The effect of obesity on chronic respiratory diseases: pathophysiology and therapeutic strategies". CMAJ 174 (9): 1293-9. doi:10.1503/cmaj.051299. PMC 1435949. PMID 16636330.

Sachpazidis, Ilias (2008)., Image and Medical Data Communication Protocols for Telemedicine and Teleradiology (dissertation), Department of Computer Science, Technical University of Darmstadt, Germany, 10 J uly 2008.

Stotzer, R.: "Comparison of Hate Crime Rates Across Protected and Unprotected Groups", Williams Institute, 2007-06. Retrieved on 2012-03-17. "A hate crime or bias motivated crime occurs when the perpetrator of the crime intentionally selects the victim because of his or her membership in a certain group." 
Streissguth, Tom (2003). Hate Crimes (Library in a Book), p.3. ISBN 0-8160-4879-7.

Woodhouse R (2008). "Obesity in art: A brief overview". Front Horm Res. Frontiers of Hormone Research 36: 271-86. doi:10.1159/000115370. ISBN 978-3-8055-8429-6. PMID 18230908.

Yekini N.A., and Oyeyinka I.K. (2013), Management information System "Mordern Perspectives" Hasfem Publication

Yekini Nureni A., and Lawal Olawale N., (2012), Information Communication and Technology "Mordern Perspective" Hasfem Publication ISBN: 978-978-919-947-1 